the authors feel some unease at the organisation of the book is indicated by their injunction to begin at chapter 7 ! That is scarcely necessary; chapter 1 is a good enough starting point, but new readers should be warned that chapters 7 and 9 are misplaced.

Having disposed of this minor criticism,
I can welcome this book with wholehearted admiration. The topic could so easily have led to a diffuse descriptive text, whereas what is presented is analytical and tightly argued. Each chapter is multiply subdivided which makes for easy reference. Lest anyone be concerned about the command of language of two German authors, Schulz and Schirmer write in a lucid and, at times, elegant English that is never less than a pleasure to read. All in all a totally recommendable book.

C. C. F. Blake is Lecturer in Molecular Biophysics at the University of Oxford, UK.

\section{Welcome enzymology}

\section{G. Lowe}

Enzymatic Reaction Mechanisms. By C. Walsh. Pp.978. (Freeman: San Francisco and Reading, 1979.) $£ 18.30$.

Enzymology is a subject which has relevance to and devotees from a wide range of disciplines. In this most welcome addition to a growing number of texts the author's approach is based on the chemistry of the reactions catalysed. In this way he has collated the transformations of metabolites in biological systems into a relatively few types of chemical reaction.

The book is in five main sections. In Section I the chemistry of the reactions to be dealt with in the remainder of the book is considered and general comments made on enzyme specificity and catalysis. Section II is concerned with enzyme catalysed group transfer reactions. Acyl-transfer being the most thoroughly studied is considered first. Unfortunately a highly significant paper concerning the catalytic triad of amino acid residues in the serine proteases appeared too late to influence the discussion in the text, but was incorporated as a footnote. This is a nightmare any author faces who attempts to survey a rapidly developing subject.

For a textbook that is devoted to enzymic reaction mechanisms, it is refreshingly free from those algebraic expressions which make enzyme kinetics look so formidable. There is however a very useful account of the application of kinetic isotope effects and reversible inhibition of enzyme catalysed reactions. Glutamyl- and amino-transfer reactions are the subject of the next chapter and this is appropriately followed by two chapters on phosphoryl transfer which includes discussions on phosphatases, ATPases, phosphodiesterases and kinases. This group of enzymes has, however, been the focus of a good deal of attention in the last few years, and inevitably therefore some highly significant experiments concerning the mechanism of these enzymes do not appear. Nucleotidyl and pyrophosphoryl, and glycosyl transfer reactions form the remaining chapters of this section.
Section III which consists of seven chapters focuses on enzymes and their cofactors which catalyse oxidations and reductions. Enzymes using nicotinamide, flavin and pterin co-enzymes are discussed first and this is followed by metalloenzymes which utilise copper or iron as the redox component in catalysis. Finally molecular oxygen as an oxidising agent is discussed in which one (mono-oxygenases) or both oxygen atoms (dioxygenases) are used.

Section IV is concerned with enzymecatalysed eliminations, isomerisations and rearrangements. A general theme is less evident in this section. Eliminations and isomerisation are however usually general acid-general base catalysed reactions, whilst rearrangements, which are fairly rare in enzymology, are often dependent on co-enzyme $\mathrm{B}_{12}$.

\section{Scope and applications of enzymology}

\section{Keith F. Tipton}

The Nature of Enzymology. By R.L. Foster. Pp.383. (Croom Helm: London, 1979.) Hardback £19.95; paperback $£ 9.95$.

THIS book was an ambitious undertaking in that the author has attempted to survey the properties and function of enzymes and the medical, analytical and technological applications of enzymology at a level that would be suitable for undergraduates reading biochemistry and related subjects such as medicine, pharmacy, and applied biology. In trying to cover such a wide field it is, perhaps, not surprising that some topics are treated in scant detail; for example, there is no treatment of the kinetic analysis of enzyme reactions involving more than one substrate, the treatments of allosteric and cooperative effects are not sufficiently detailed and lack correlation with structural data; and the treatment of enzyme-linked immunoassays is too brief to explain the approaches adequately. Many of these deficiencies are, however, ameliorated in part by the well
Section V covers enzymic reactions that make and break carbon-carbon bonds, so bringing together some of the most biosynthetically versatile reactions, and which frequently require cofactors, such as thiamine pyrophosphate, biotin and pyridoxal phosphate. In the final chapter of this section the chemical logic of metabolic pathways is discussed.

The author is to be congratulated on producing an exciting and very readable account of the chemistry of enzymatic reaction mechanisms. The presentation is excellent, and the text is remarkably free from trivial error.

G. Lowe is in the Dyson Perrins Laboratory, University of Oxford, UK.

chosen references to original papers and reviews.

The mathematical analysis of enzyme behaviour is the weakest aspect of this book and the section on reversible inhibitors contains some confusing errors. In some places, such as the section on the regulation of enzyme systems, the purpose of the mathematical treatments is not made clear.

The strength of this book lies in its treatment of the more applied aspects of the subject, and the sections on the applications and limitations of enzymological methods in medicine and industry are clearly presented and well illustrated with examples. The use of numerous examples to illustrate the points made throughout the book are most valuable and make it enjoyable to read. Because of its somewhat cursory treatments of some important aspects of enzymology I could not recommend this as a textbook for students reading biochemistry as their main subject. Despite the criticisms mentioned above, however, the book might be used advantageously for courses in which biochemistry was a peripheral subject and it could be recommended to anyone wishing to get an idea of the present scope and applications of enzymology.

Keith F. Tipton is Professor of Biochemistry at Trinity College, Dublin, Eire. 